\title{
PERFIL DE SENSIBILIDADE MICROBIANA IN VITRO DE LINHAGENS PATOGÊNICAS DE Escherichia coli ISOLADAS DE CARNE BOVINA
}

\author{
Samira Pirola Santos Mantilla ${ }^{1}$, Robson Maia Franco ${ }^{2}$ \\ ${ }^{1}$ Pesquisadora em nível de Doutorado na Universidade Federal Fluminense (UFF), Niterói - RJ. ${ }^{2}$ Professor Associado II da \\ Universidade Federal Fluminense (UFF), Niterói - RJ
}

\section{RESUMO}

O presente trabalho estudou a resistência antimicrobiana de linhagens de Escherichia coli (EPEC A, EPEC $B$, EPEC C, EIEC A e EIEC B) isoladas de amostras de carne bovina. O teste de sensibilidade aos antimicrobianos foi realizado por meio do método de disco-difusão padronizado internacionalmente pelo Comitê Nacional de Padrões Clínicos Laboratoriais. As linhagens apresentaram resistência para a maioria dos antibióticos testados. A gentamicina foi o antibiótico mais eficiente, desde que $84,9 \%$ das linhagens apresentaram sensibilidade ao mesmo. Ainda, a cefoxitina foi o agente antimicrobiano menos eficiente, com alta porcentagem de linhagens resistentes. A multiresistência aos antimicrobianos é de suma importância para a saúde pública, à medida que patógenos resistentes podem ser veiculados aos consumidores pela ingestão de produtos de origem animal, dificultando o tratamento de infecções bacterianas e aumentando a resistência das bactérias aos antibióticos.

Palavras-chave: multirresistência; antibióticos; saúde pública; infecções bacterianas; patógenos de origem alimentar.

\section{PROFILE OF MICROBIAL SENSITIVITY IN VITRO PATHOGENIC STRAINS OF Escherichia coli ISOLATED FROM BEEF}

\begin{abstract}
This study aimed to analyze the antimicrobial resistance of Escherichia coli strains (EPEC A, EPEC B, EPEC $C$, EIEC A e EIEC B) isolated from bovine meat. The antimicrobial susceptibility test was evaluated using the technique described by the National Committee for Clinical Laboratory Standards. The strains were resistant to most antibiotics tested, and gentamicin showed the best efficiency, with $84.9 \%$ of the strains showing sensitivity. In addition, cefoxitin was the least effective antimicrobial agent, have a higher percentage of resistant strains. The multidrug resistance to antimicrobials is a finding of great importance to public health, as resistant pathogens may be conveyed to consumers by the ingestion of animal products, making difficult the treatment of bacterial infections and increasing the occurrence of bacteria resistant to antibiotics.

Keywords: multidrug resistance; antibiotics; public health; bacterial infections; foodborne pathogens.
\end{abstract}




\section{INTRODUÇÃO}

A utilização dos antimicrobianos gerou grande otimismo em relação à prevenção e ao tratamento dos processos infecciosos (MONTELLI; SADATSUNE, 2001). Os antimicrobianos são amplamente utilizados na clínica veterinária e o uso indiscriminado destes fármacos contribui com o aumento progressivo da resistência bacteriana (MOTA et al., 2005).

Nos sistemas de produção agropecuária, os antimicrobianos são empregados com três diferentes propósitos: a) tratamento de infecções bacterianas específicas, b) prevenção de infecções bacterianas, e c) aditivo alimentar, como promotor de crescimento (ANDREOTTI; NICODEMO, 2004). Os agentes antimicrobianos são fornecidos aos bovinos, principalmente, para controle de abscessos e prevenir ou tratar doenças respiratórias e relacionadas com estresse de viagem com reflexos na conversão alimentar (MCDERMOTT et al.,2002). No entanto, seu uso no Brasil é indiscriminado e abusivo, muitas vezes sem orientação adequada de médicos veterinários, e, ao contrário dos antimicrobianos da linha humana, a maioria das medicações veterinárias é comercializada sem qualquer tipo de controle oficial.

Apesar da comprovada contribuição no desempenho animal, os antimicrobianos promotores de crescimento passaram a ser vistos como fatores de risco para a saúde humana, devido ao potencial desenvolvimento da resistência bacteriana cruzada em humanos (BARRETO, 2007). Os antimicrobianos não devem ser usados como uma alternativa fácil para obtenção de boas práticas na criação e produção de animais de produção (MANTILLA et al., 2008).

A origem da resistência pode ser genética ou não e, independente de qual seja a forma de maior importância neste processo, o número de novas bactérias resistentes e patogênicas para os animais e humanos cresce mais rápido do que a capacidade dos laboratórios e indústrias produzirem novos fármacos (MOTA et al., 2005).

Diversos pesquisadores em microbiologia de alimentos relataram resistência multivariada de cepas de Escherichia coli (E. coli) isoladas a partir de diferentes alimentos como Oliveira et al. (1999) (hambúrguer), Schroeder et al. (2002) (diversos alimentos), Franco (2002) (carne suína), Reyes et al. (2004) (produtos cárneos), Martins et al. (2003) (produtos de origem animal), Kasnowski (2004) (carne bovina), Santo (2006) (carne moída), Martinéz e Villalobos (2008) (alimentos variados).

Com base nos fatores de virulência, manifestações clínicas, epidemiologia e sorotipagem, as cepas de E. coli consideradas patogênicas são agrupadas em cinco classes: EPEC (E. coli enteropatogênica clássica), EIEC (E. coli enteroinvasora), ETEC (E. coli enterotoxigênica), EHEC (E. coli enterohemorrágica) e EaggEC (E. coli enteroagregativa) (TRABULSI; TOLEDO, 1989) Os sintomas das gatroenterites ocasionadas pelas cepas patogênicas de $E$. coli, consistem principalmente em diarréia. Porém, a EHEC possui a capacidade de causar a colite hemorrágica, a qual pode evoluir para a síndrome urêmica hemolítica (SUH). A EPEC é um importante microrganismo causador de gastroenterites em crianças e possui um número restrito de sorotipos. Já as cepas de EIEC não possuem flagelos, fermentam tardiamente ou não a lactose, são capazes de penetrar em células epiteliais e causar manifestações clínicas semelhantes às infecções causadas por Shigella (FRANCO; LANDGRAF, 2008)

A resistência aos agentes antimicrobianos tornou-se uma das principais preocupações para a saúde humana, mas também está se tornando 
problema em medicina veterinária. Os antimicrobianos são usados mundialmente para tratamento e profilaxia de doenças infecciosas em animais de produção, equinos e animais de companhia e como promotores de crescimento. Em muitos estudos observou-se que o uso de antimicrobianos em animais contribuiu para o desenvolvimento de resistência antimicrobiana em humanos, pois muitas classes de antimicrobianos usadas em animais também são empregadas em seres humanos para tratar doenças graves, ocorrendo falha terapêutica, devido à transferência de bactérias resistentes pela cadeia alimentar (ARIAS; CARRILHO, 2012) Logo, torna-se necessário o estudo do perfil de resistência antimicrobiana de patógenos oriundos de alimentos de origem animal com o intuito de verificar o percentual de cepas resistentes aos antimicrobianos mais utilizados na terapia humana, enfatizando a importância da transmissão de cepas resistentes através de alimentos de origem animal (MARTINÉZ; VILLALOBOS, 2008) ou de resíduos de antimicrobianos para os consumidores de produtos cárneos (SANTOS, 2009).

O objetivo dessa pesquisa foi verificar o perfil de resistência microbiana de linhagens de $E$. coli patogênicas ( $E$. coli enteropatogênica sorotipo A, B e C e E. coli enteroinvasora) isoladas a partir de carne bovina.

\section{MATERIAL E MÉTODOS}

Foi determinada a sensibilidade de 113 cepas patogênicas de $E$. coli oriundas de carne bovina adquiridas em comércios varejistas no município de Niterói, RJ, sorogrupos E. coli enteropatogênica sorotipo A (EPEC A) (026, 055, 0111, 0119), E. coli enteropatogênica sorotipo B (EPEC B) (0114 e 0125, 0142, 0158), E. coli enteropatogênica sorotipo C (EPEC C) (086, 0126, 0127, 0128) e E. coli enteroinvasora sortipo A $($ EIEC A) $(028,029,0152), \quad$ E. coli enteroinvasora sorotipo B (EIEC B) (0112), pelo método de disco-difusão (NCCLS, 2003).

Foram preparadas placas de Petri com 20 a $25 \mathrm{~mL}$ do meio padrão Müeller-Hinton. Os subcultivos estavam armazenados sob refrigeração no ágar tripticase se soja. Após o repique de cada colônia para um tubo contendo o mesmo ágar inclinado, foram adicionados $4 \mathrm{~mL}$ de água destilada, homogeneizados com auxílio de uma alça fllambada e ajustada a suspensão para o padrão número um da escala de Mc Farland: $1 \mathrm{~mL}$ de $\mathrm{BaCl}_{2}$ a $1 \%+99 \mathrm{~mL}$ de $\mathrm{H}_{2} \mathrm{SO}_{4}$ a $1 \%(0,36 \mathrm{~N})$ que corresponde a $3,8 \times 10^{8}$ microrganismos por $\mathrm{mL}$.

Com o uso de um zaragatoa estéril, o inóculo foi espalhado homogeneamente na superfície do meio e após alguns minutos colocados polidiscos com auxílio de uma pinça previamente flambada e esfriada. Os seguintes antimicrobianos foram utilizados no teste: amicacina, ampicilina, cefalotina, cefoxitina, cloranfenicol, gentamicina, nitrofurantoína, sulfazotrim e tetraciclina. Após a semeadura, as placas com os isolados foram incubadas a $37^{\circ} \mathrm{C}$ por 24 horas.

O resultado consistiu na medição do tamanho da zona de inibição com um halômetro e na classificação das cepas em sensíveis, intermediárias ou resistentes de acordo com as normas técnicas recomendadas internacionalmente (NCCLS, 2003).

\section{RESULTADOS}

$\mathrm{Na}$ Tabela estão sumarizados os resultados dos testes de sensibilidade microbiana de $E$. coli frente aos antimicrobianos testados.

Pelos dados da Tabela 1, verificou-se que as cepas patogênicas isoladas foram resistentes à maioria dos antimicrobianos utilizados na pesquisa. A cefoxitina foi o antimicrobiano menos eficaz por apresentar maior percentual de cepas resistentes. Em contrapartida, a gentamicina 
apresentou o menor percentual de linhagens

resistentes.

Tabela 1. Sensibilidade microbiana na prova com difusão com discos em 113 linhagens de E. coli isoladas de carne bovina, Niterói, RJ, 2005.

\begin{tabular}{lccc}
\hline & Sensível & Resistente & Intermediário \\
\cline { 2 - 4 } Antimicrobianos & $\mathrm{n}^{0}$ de linhagens & $\mathrm{n}^{\circ}$ de linhagens \\
sensíveis $/ \mathrm{n}^{\circ}$ total de & isolados $(\%)$ & $\begin{array}{c}\text { distentes } / \mathrm{n}^{\circ} \text { total de } \\
\text { isolados }(\%)\end{array}$ & $\begin{array}{c}\text { resistentes } / \mathrm{n}^{\circ} \text { total de } \\
\text { isolados }(\%)\end{array}$ \\
Amicacina & $87(77)$ & $87 / 113(77)$ & - \\
Ampicilina & $25(22,12)$ & $7((6,2)$ & $81(71,7)$ \\
Cefalotina & $100(88,5)$ & $1(0,88)$ & $12(10,6)$ \\
Cefoxitina & $107(94,69)$ & $5(4,42)$ & $1(0,88)$ \\
Cloranfenicol & $67(59,2)$ & $46(40,8)$ & - \\
Gentamicina & $7(6,2)$ & $96(84,9)$ & $10(8,84)$ \\
Nitrofurantoína & $104(92,50)$ & $9(7,5)$ & - \\
Sulfazotrim & $31(27,4)$ & $79(69,9)$ & $3(2,65)$ \\
Tetraciclina & $18(15,9)$ & $92(81,4)$ & $3(2,65)$
\end{tabular}

$\mathrm{n}^{\circ}=$ número; \% =porcentagem

\section{DISCUSSÃO}

A realização do teste de sensibilidade antimicrobiana de E. coli é de suma importância, visto que diversos pesquisadores vem relatando uma elevada taxa de resistência dos sorotipos isolados de diferentes alimentos. Esta afirmação é fundamentada nesta pesquisa em que a maioria das cepas patogênicas de E. coli apresentou grande espectro de resistência aos antimicrobianos testados, principalmente à cefoxitina, nitrofurantoína, cefalotina , amicacina e cloranfenicol. Estes resultados têm implicações importantes em relação ao uso prudente de agentes antimicrobianos e à possível propagação de resistência antimicrobiana em populações bacterianas, o que dificultaria um tratamento de doenças de origem alimentar e até mesmo de outros tipos de enfermidades. A susceptibilidade foi maior para gentamicina, seguido pela tetraciclina e sulfazotrim. Oliveira et al. (1999) corroboraram com os resultados deste trabalho ao verificarem que os cultivos de $E$. coli isolados de hambúrgueres eram 100\% sensíveis a gentamicina.

Schroeder et al. (2002), ao isolarem 361 cepas de E. coli 0157 em Washington, demonstraram que a maioria (61\%) foi sensível aos antibióticos testados, sendo que o maior índice de resistência foi somente de 27\% para tetraciclina e as cepas demonstraram-se pouco resistentes a cefalotina (17\%) diferentemente dos resultados encontrados no presente estudo, provavelmente devido a diferentes localizações geográficas onde os estudos foram conduzidos. Além disso, os sorogrupos testados foram diferentes, EHEC no caso dos pesquisadores citados, enquanto nessa pesquisa foram testados somente os sorogrupos EPEC e EIEC.

Os achados inclusos na Tabela 1 estão em conformidade com os de Franco (2002), que afirma serem as cepas de E. coli resistentes em sua grande maioria aos antibióticos testados. A similaridade também é demonstrada na susceptibilidade a gentamicina (100\%). Da mesma forma, Reyes et al. (2004) verificaram que as cepas de E. coli isoladas produtos cárneos foram sensíveis à gentamicina e tetraciclina.

Martins et al. (2003) encontraram resultados semelhantes, onde aproximadamente $63 \%$ das cepas de E. coli testadas demonstraram resistência entre dois a 11 antibióticos. $\mathrm{Na}$ maioria das linhagens foi constatado o caráter de múltipla resistência. Contudo, ao contrário do presente estudo, os autores observaram que o 
maior nível de resistência foi para a sulfonamida $(69,3 \%)$ seguida da tetraciclina $(43,4 \%)$ e que as cepas testadas apresentaram maior susceptibilidade a cefalotina.

Kasnowski (2004) também observaram que as cepas de $E$. coli isoladas de carne bovina inteira e moída oriundas de estabelecimentos comerciais do município do Rio de Janeiro, RJ, apresentaram grande espectro de resistência, principalmente frente a ampicilina (11,32\%), cefalotina (11,11\%) e amicacina (10,06\%). Porém, essa pesquisadora relatou que a maior susceptibilidade foi observada para a cefoxitina, gentamicina e tetraciclina (10,75\%), diferentemente dos achados nesse estudo, onde a cefoxitina foi 0 antimicrobiano com maior percentual de cepas resistentes. Em relação à gentamicina e tetraciclina, os dados corroboram com os da presente pesquisa.

A maioria das cepas estudadas foi sensível ao sulfazotrim e todas as cepas demonstraram resistência multivariada para os antimicrobianos testados. Entretanto, Martín et al. (2005) ao analisarem a resistência antimicrobiana de 72 cepas de E. coli isoladas de conteúdo cecal de gado corte, constataram que menos de $3 \%$ das cepas eram multirresistentes e o percentual de resistência mais elevado foi de $11 \%$ para a sulfametoxazol / trimetoprim.

Santo (2006) também relatou que a maioria das cepas (80\%) de E. coli isoladas de carne moída adquiridas em açougues da cidade de Taquaritinga, SP foram resistentes a múltiplos antimicrobianos. Todavia, a amicacina e gentamicina apresentaram resultado considerado satisfatório com 20\% de resistência. O mesmo autor relatou elevada resistência (80\%) para tetraciclina, em contraste com os resultados obtidos nesse experimento.

Em relação à ampicilina, a maioria das cepas analisadas apresentou resistência intermediária. Porém, Martinéz e Villalobos (2008) verificaram que dentre os antibióticos testados (cloranfenicol, ampicilina, cefotaxime, ceftazidime, piperacilina, gentamicina, tobramicina, ácido nalidixico, levofloxacina, ciprofloxacina, trimetroprim-sulfametoxazol e tetraciclina), a maior resistência das cepas de $E$. coli isoladas de alimentos foi observada para a ampicilina.

As cepas testadas foram 100\% multiresistentes a três ou mais antimicrobianos. Hiko et al. (2008) constataram multirresistência a três ou mais antimicrobianos apenas em 7 / 31 $(22,6 \%)$ cepas de E. coli O157: $\mathrm{H} 7$ isoladas de carnes bovina, cordeiro e carneiro, cabra na Etiópia. Além disso, esses autores verificaram que as cepas isoladas foram suscetíveis (100\%) à amicacina, cloranfenicol, gentamicina, kanamicina, ácido nalidíxico, norfloxacina, polimixina B e trimetoprim-sulfametoxazol.

Foi observada resistência ao cloranfenicol e nitrofurantoína em respectivamente 59,2\% e $92,5 \%$ das linhagens isoladas. O uso destes antimicrobianos em animais de produção é proibido no Brasil, conforme a Instrução Normativa número 9, de 27 de junho de 2003 (BRASIL, 2003). Os nitrofuranos constituem um grupo de substâncias com ação antimicrobiana, entre as quais se enquadram a furazolidona, a furaltadona, a nitrofurantoína e a nitrofurazona. Essas substâncias possuem um amplo espectro de ação e são ativas contra bactérias, coccídeos, e alguns fungos. Por esse motivo, os nitrofuranos foram utilizados durante décadas no tratamento de doenças, na profilaxia e como promotores de crescimento, em algumas espécies de animais, principalmente, suínos e aves. Como essas substâncias possuem efeitos carcinogênicos e mutagênicos no organismo, foi proibido o seu uso em animais destinados à produção de alimentos (MOITA et. al., 2012). Os efeitos adversos mais graves provocados pelo cloranfenicol em seres humanos estão relacionados com sua capacidade de causar diminuição na atividade da medula 
óssea, a qual é reversível e está relacionada à dose, e aplasia (anemia aplástica), a qual é irreversível e não apresenta relação dose resposta (WHO, 2004).

A variação da resistência aos antimicrobianos testados, conforme os resultados encontrados no presente estudo, coloca em alerta a comunidade científica, em função do perigo em potencial do consumidor ao ingerir carnes, cujas cepas contaminantes apresentam este perfil. O perfil de sensibilidade microbiana de linhagens de E. coli isoladas de animais deve ser alvo de sistemas de monitoramento, preferencialmente em caráter multicêntrico, a fim de nortear medidas sanitárias de controle.Tal aspecto deve ser visto com extremo rigor, pois, possivelmente estas amostras devem ter sido oriundas de animais que foram submetidos a tratamento por antimicrobianos sem ter sido respeitado o período de carência. Além disso, o surgimento de agentes bacterianos resistentes a múltiplos antimicrobianos em produtos de origem animal no Brasil pode ser creditado ao uso indiscriminado, abusivo e sem respaldo de testes de sensibilidade para estes fármacos em animais de produção.

A E. coli é uma das principais espécies onde plasmídeos contendo genes envolvidos no processo de resistência múltipla aos antimicrobianos vêm sendo caracterizados. Esta característica está relacionada a sua ampla distribuição ambiental e propensão a albergar elementos genéticos móveis, em especial os plasmídeos. A conjugação, transposição e recombinação são amplamente incriminadas com a evolução da resistência bacteriana aos antimicrobianos (COSTA, 2007).

\section{REFERÊNCIAS}

ANDREOTTI, R.; NICODEMO, M. L. F. Uso de antimicrobianos na produção de bovinos e desenvolvimento de resistência. Campo Grande: Embrapa Gado de Corte, 2004.

ARIAS, M. V. B.; CARRILHO, C. M. D. M. Resistência antimicrobiana nos animais e no ser humano. Há motivo para preocupação? Semina: Ciências Agrárias, v. 33, n. 2, p. 775-790, 2012. DOI: 10.5433/1679-0359.2012v33n2p775

\section{BARRETO, M. S. R. Uso de extratos vegetais} como promotores do crescimento em frangos de corte. 2007. 51 f. Dissertação (Mestrado em Agronomia) - Escola Superior de Agricultura Luiz de Queiroz, Universidade de São Paulo, Piracicaba.

BRASIL. Ministério da Agricultura, Pecuária e Abastecimento. Instrução normativa $\mathbf{n}^{\circ} \mathbf{9}$, de 27 de junho de 2003. Proibir a fabricação, a manipulação, o fracionamento, a comercialização, a importação e o uso dos princípios ativos cloranfenicol, nitrofuranos e os produtos que contenham estes princípios ativos, para uso veterinário e suscetível de emprego na alimentação de todos os animais e insetos. 2003. Disponível em

<http://sistemasweb.agricultura.gov.br/sislegis/acti on/detalhaAto.do?method=visualizarAtoPortalMap a\&chave $=2112258128>$. Acesso em 03 ago. 2012.

COSTA, M. M. Caracterização patotípica de isolados de Escherichia coli obtidos de suínos : presença de plasmídeos e perfil de resistência aos antimicrobianos. 2007. $141 \mathrm{f}$. Tese (Doutorado). Universidade Federal do Rio Grande do Sul, Porto Alegre, RS.

FRANCO, R. M. Escherichia coli: ocorrência em suínos abatidos na Grande Rio e sua viabilidade experimental em lingüiça frescal tipo toscana. 2002. 153f. Tese (Doutorado em Medicina Veterinária) - Departamento de Tecnologia de 
Alimentos, Universidade Federal Fluminense, Niterói.

FRANCO, B. D. G. M.; LANDGRAF, M. Microbiologia dos alimentos. São Paulo: Atheneu, 2008.

HIKO, A.; ASRAT, D.; ZEWDE, G. Occurrence of Escherichia coli O157:H7 in retail raw meat products in Ethiopia. The Journal of Infection in Developing Countries, v.2, n.5, p. 389-393, 2008. doi:10.3855/jidc.203

KASNOWSKI, M. C. Listeria spp., Escherichia coli: isolamento, identificação, estudo sorológico e antimicrobiano em corte de carne bovina (alcatra) inteira e moída. 2004. 110 f. Dissertação (Mestrado em Higiene Veterinária e Processamento Tecnológico de Produtos de Origem Animal) - Departamento de Tecnologia de Alimentos, Universidade Federal Fluminense, Niterói.

MANTILLA, S. P. S.; FRANCO, R. M.; OLIVEIRA, L. A. T.; SANTOS, E. B.; GOUVÊA, R.

Resistência antimicrobiana de bactérias do gênero Listeria spp. isoladas de carne moída bovina. Brazilian Journal of Veterinary Research and Animal Science, v. 45, n. 2, p. 116-121, 2008.

MARTÍN, B. S.; BRAVO, V.; BORIE, C. Evaluación de la resistencia antimicrobiana en ganado bovino en Chile, utilizando E. coli como bacteria indicadora. Archivos Brasileiro de Medicina Veterinaria, v. 37, n. 2, p. 117-123, 2005. doi: 10.4067/S0301-732X2005000200005

MARTÍNEZ, R. E.; VILLALOBOS, L. B.

Susceptibilidad antimicrobiana de cepas de Escherichia coli aisladas de alimentos y aguas residuales en Cumaná, Venezuela. Saber, Universidad de Oriente, v. 20, n. 2, p. 172-176, 2008

MARTINS, S.C.S.; LIMA, J.R.; ALMADA, J.S.; PEREIRA, A.I.B. "Screening" de linhagens de
Escherichia coli multiresistentes a antibióticos, em alimentos de origem animal no estado do Ceará, Brasil. Higiene Alimentar, v.17, n.104/105, p.7176, 2003.

MCDERMOTT, P. F.; ZHAO, S.; WAGNER, D. D.; SIMJEE, S.; WALKER, R. D.; WHITE, D. G. The food safety perspective of antibiotic resistance.

Animal Biotechnology, v. 13, n. 1, p. 71-84, 2002. http://dx.doi.org/10.1081/ABIO-120005771

MOITA, S. R.; PORTZ, A. J.; MARTINS, A. L.; ROCHA, R. S.; FEIJÓ, L. D.; DANTAS, R. M. Inocuidade de alimentos pelo controle de resíduos de nitrofuranos no Brasil. Disponível em:

<http://www.sovergs.com.br/site/38conbravet/resu mos/72.pdf>. Acesso em 03 ago. 2012.

MONTELLI, A. C.; SADATSUNE, T.

Antibioticoterapia para o clínico. Rio de Janeiro: Sociedade Brasileira de Microbiologia, 2001.

MOTA, R. A.; SILVA, K. P. C.; FREITAS, M. F. L.; PORTO, W. J. N.; SILVA, L. B. G.. Utilização indiscriminada de antimicrobianos e sua contribuição a multirresitência bacteriana.

\section{Brazilian Journal of Veterinary Research and}

Animal Science, v. 42, n. 6, p. 465-470, 2005.

NCCLS - National Committee for Clinical Laboratory Standards. Performance Standars for Antimicrobial Disk Susceptibility Test; Approved Standard - Eight Edition. NCCLS Document M2-AB, v.23, n1, 2003.

OLIVEIRA, L.A.T.; FERREIRA, T.; FRANCO, R. M.; CARVALHO, J. C. A. P. Enumeração de Escherichia coli e Enterococcus em amostras de hambúrguer de frango, comercializadas em Niterói- RJ. Avaliação da sensibilidade a antimicrobianos das cepas isoladas. Higiene Alimentar, v.13, n.63, p.49-55, 1999.

REYES, M. S; DURÁN, C. T.; PRADO, V. J. Perfil de susceptibilidad a los antimicrobianos en cepas 
de E coli productoras de Shiga toxina (STEC) aisladas de infecciones humanas y de alimentos.

Revista Médica de Chile, v.132 n.10, p. 12111216, 2004.

SANTO, E. Detecção de Escherichia coli patogênica extraintestinal e análise de seus fatores de virulência e perfil de resistência antimicrobiana em carne moída de açougues do município de Taquaritinga, SP, Brasil. 2006. $118 \mathrm{f}$. Tese (Doutorado em Microbiologia Agropecuária) - Faculdade de Ciências Agrárias e Veterinárias - UNESP, Jaboticabal.

SANTOS, E. V. A. C. Controlo de resíduos de substâncias farmacologicamente activas nos animais de produção e seus derivados. Comparação dos diferentes cenários na União Europeia. 2009. 55 f. Dissertação (Mestrado Integrado em Medicina Veterinária) - Faculdade de Medicina Veterinária, Universidade Técnica de Lisboa, Lisboa.

SCHROEDER, C. M.; ZHAO, C., DEBROY, C.; TORCOLINI, J.; ZHAO, S.; WHITE, D. G.; MCDERMOTT, P. F.; WALKER, R. D.; MENG, J. Antimicrobial resistance of Escherichia coli 0157 isolated from humans, cattle, swine, and food.

Applied and Environmental Microbiology. v. 68, n.2, p.576-581, 2002.

http://dx.doi.org/10.1128/AEM.68.2.576-581.2002

TRABULSI, L. R; TOLEDO, M. R.F. Escherichia. In: TRABULSI, L. R. Microbiologia. 2. ed. São Paulo: Atheneu, 1989.

WHO (World Health Organization). Evaluation of certain veterinary drug residues in food. Sixtysecond report of the Joint FAO/WHO Expert Committee on Food Additives. WHO Technical

Report Series n 925, Geneve, 2004. 